Pablo Galindo-Moreno

Ildefonso Moreno-Riestra

Gustavo Avila

Miguel Padial-Molina

Jorge A. Paya

Hom-Lay Wang

Francisco O'Valle

\section{Effect of anorganic bovine bone to autogenous cortical bone ratio upon bone remodeling patterns following maxillary sinus augmentation}

Authors' affiliations:

Pablo Galindo-Moreno, Oral Surgery and Implant

Dentistry Department, School of Dentistry, University

of Granada, Granada, Spain

Pablo Galindo-Moreno, Ildefonso Moreno-Riestra,

Miguel Padial-Molina, Gustavo Avila, Hom-Lay Wang,

Department of Periodontics and Oral Medicine, School of Dentistry, University of Michigan, Ann Arbor, MI,

USA

Jorge A. Paya, Francisco O'Valle, Department of

Pathology and IBIMER, School of Medicine, University

of Granada, Granada, Spain

\section{Corresponding author:}

Pablo Galindo-Moreno

C/Recogidas, $395^{\circ}$ Izq

I 8005 Granada

Spain

Tel.: + 34958520658

Fax: + 34958520658

e-mail: pgalindo@ugr.es/pablogm@umich.edu

Date:

Accepted I9 August 2010

To cite this article:

Galindo-Moreno P, Moreno-Riestra I, Avila G, Padial-

Molina M, Paya JA, Wang H-L, O'Valle F. Effect of anorganic bovine bone to autogenous cortical bone ratio upon bone remodeling patterns following maxillary sinus augmentation.

Clin. Oral Impl. Res. 22, 20I I; 857-864.

doi: IO.I I I I/j.I600-050I.2010.02073.X

Key words: bone grafting, bone remodeling, dental implants, maxillary sinus, osteopontin, TRAP-1 protein

\begin{abstract}
Introduction: Maxillary sinus augmentation is a predictable implant site development technique, although several local and systemic factors may influence outcomes. The aim of this study was to evaluate healing patterns and bone remodeling activity following the use of two different graft mixtures for maxillary sinus augmentation.
\end{abstract}

Materials and methods: Patients in need of maxillary sinus augmentation were randomly assigned to two different groups. A graft mixture using a $50 \%$ autologous bone (AB) to $50 \%$ anorganic bovine bone $(A B B)$ ratio was used in group 1, while a $20 \% A B$ to $80 \% A B B$ ratio was utilized for group 2 . After a 6-month healing period, bone core biopsies were harvested for histological, histomorphometrical, and immunohistochemical analyses.

Results: Twenty-eight subjects participated in this study. No statistically significant differences were found between groups in regards to vital bone and non-mineralized tissue proportions. Higher number of osteoid lines (18.05 \pm 10.06 in group 1 vs. $9.01 \pm 7.53$ in group 2; $P=0.023)$ and higher cellularity, particularly regarding the number of osteocytes $(631.85 \pm 607.98$ in group 1 vs. $219.08 \pm 103.26$ in group $2 ; P=0.002$ ), were observed in specimens from group 1. Differences in expression patterns of osteopontin and tartrate-resistant acid phosphatase were also detected between groups.

Conclusion: $A B$ to $A B B$ ratio appears to influence bone remodeling patterns and cell content following maxillary sinus augmentation procedures. Similar proportion of vital bone was found in specimens obtained from both groups. More cellular presence was observed in samples containing higher proportions of $A B$.

Since the introduction of maxillary sinus augmentation as an implant site development modality (Boyne \& James I980), several modifications of the lateral approach technique have been developed (Vercellotti et al. 200I; Lundgren et al. 2004; Peleg et al. 2004; Soltan \& Smiler 2005; Martos Diaz et al. 2007). Likewise, a variety of materials (i.e. autografts, allografts, alloplasts, and xenografts) have been applied for sinus grafting, typically associated with satisfactory clinical outcomes (Wheeler I997; Wallace \& Froum 2003; Del Fabbro et al. 2004). According to the current understanding, there is no evidence supporting the superiority of any particular bone graft in terms of implant survival or absence of complications at the recipient site (Browaeys et al. 2007; Nkenke \& Stelzle 2009). In light of this information, many clinicians have accepted as a general consensus the concept that maxillary sinus augmentation is predictable, regardless of the grafting material used. However, it is important to keep in mind that long-term clinical success relies on the formation of a functional vital bone-graft complex, which is influenced by the type of graft used (Watzek et al. 2006).

Autologous bone $(\mathrm{AB})$ and anorganic bovine bone $(\mathrm{ABB})$ are the biomaterials with the strongest literature support in sinus augmentation. It is a general belief that $\mathrm{AB}$ is the gold standard bone grafting material, given its unique osteoconductive, osteoinductive, and osteogenic properties. However, intense bone remodeling leading to excessive bone resorption may occur when $\mathrm{AB}$ is used as a sole material for sinus augmentation (Schlegel et al. 2003). In order to prevent this unfavorable event, its use in combination with a slowly absorbable material has been proposed (Yildirim et al. 200I; Hallman et al. 2002b). 
$\mathrm{ABB}$ presents a notable slow resorption rate, being able to remain stable for years (Sartori et al. 2003; Traini et al. 2007). Furthermore, $\mathrm{ABB}$ possesses remarkable osteoconductivity, as well as an ability to allow revascularization (Galindo-Moreno et al. 20Iob). Previous studies have reported the histologic features of bone samples obtained after the utilization of $\mathrm{AB}$ (Hallman et al. 2002 b), ABB (Ferreira et al. 2009), or a combination of them (Wallace et al. 2005; Galindo-Moreno et al. 2007). Interestingly, tissues analyzed present different characteristics depending on the nature of the grafting material applied, the proportion of materials used, and the time of sample harvesting. Therefore, some critical questions remain unanswered.

Within the limits of our knowledge, there is a paucity of controlled studies aimed at evaluating sinus augmentation outcomes at the histological level, depending on the $\mathrm{AB}$ to $\mathrm{ABB}$ ratio in a large series of patients. Hence, the objective of the present study was to evaluate tissue response and bone remodeling activity in samples obtained after using two different graft mixture ratios for maxillary sinus augmentation.

\section{Material and methods}

\section{Study design and subject recruitment}

Before subject recruitment, this prospective clinical trial was reviewed and approved by the Institutional Review Board of the University of Granada. The study was conducted according to the principles of the Helsinki's declaration for experimentation involving human subjects (Schuklenk \& Ashcroft 2000).

Totally or partially edentulous patients in need of maxillary sinus augmentation were screened and included in the study according to the following inclusion criteria: Adult patients (I 8-85 years of age) presenting a physical status according to the American Society of Anesthesiologists of I or II (http://www.asahq.org/clinical/physicalstatus.htm), no uncontrolled systemic disease, no condition known to alter bone metabolism (i.e. osteoporosis, diabetes mellitus), O'Leary plaque score $\leq 20 \%\left(\mathrm{O}^{\prime}\right.$ Leary et al. I972), and $\leq 5 \mathrm{~mm}$ of remaining bone height based on radiographic measurements over panoramic films (Wang \& Katranji 2008; Rios et al. 2009). Subjects who reported antibiotic intake within 3 months before study initiation, or long-term use ( $>6$ months) of medications known to modify bone metabolism (such as bisphosphonates and corticosteroids), women that were pregnant or attempting to get pregnant at the time of the screening, and patients that presented untreated chronic sinus conditions (i.e. cysts, tumors), sepsis, history of cancer and/or radiation to the oral cavity, or complications derived from any of these conditions affecting the sinus area, were excluded from the study. Patients who reported smoking > Io cigarettes per day (Levin et al. 2004), and consumers of > Iog of alcohol per day (Galindo-Moreno et al. 2005) were also excluded. For the statistical analysis, patients who reported smoking one or more cigarettes per day or consuming one or more alcoholcontaining drinks daily were accounted as smokers and alcohol consumers, respectively. Patients who met the inclusion and exclusion criteria were required to read, understand, and sign an informed consent before the final enrollment in the clinical trial.

\section{Surgical procedures}

Patients were requested to take an antibiotic (Amoxicillin/Clavulanate 875/I25 mg t.i.d. for Io days, starting 2 days before the surgery; or Clindamycin $300 \mathrm{mg}$ t.i.d. for ro days, starting 2 days before the surgery, in case of allergy to penicillins) to minimize the risk of infection. All surgical procedures were performed under local anesthesia (Articain, Ultracain ${ }^{\circledR}$, Aventis Inc., Frankfurt, Germany). Sinus were intervened following the technique proposed by GalindoMoreno et al. (2007), using a bone scraper (Safescraper $^{(B}$, Meta, Reggio Emilia, Italy) to harvest $A B$ from the lateral wall and expose the Schneiderian membrane. Following membrane elevation, sinus cavities were grafted with $\mathrm{AB}$ in combination with $\mathrm{ABB}$ particles ranging from 250 to $1000 \mu \mathrm{m}$ /Geistlich Bio-Oss ${ }^{1 B}$, Geistlich Pharma AG, Wolhusen, Switzerland). Two different mixtures were used, consisting of a $50 \%[\mathrm{AB}]: 50 \%[\mathrm{ABB}]$ ratio (group I) and a $20 \%[\mathrm{AB}]: 80 \%[\mathrm{ABB}]$ ratio (group 2), reported previously as an ideal composite proportion for maxillary sinus augmentation procedures (Hallman et al. 2002b). As much graft volume as necessary was used to meet the clinical goal, to a maximum of $5 \mathrm{~cm}^{3}$ of material per sinus cavity (Galindo-Moreno et al. 2008). After bone grafting, an absorbable collagen membrane (Geistlich Bio-Gide ${ }^{\mathbb{B}}$, Geistlich Pharma AG) was placed over the lateral aspect of the bony window. Then, flaps were carefully approximated and sutured with surgical silk 3/o (Laboratorio Aragó, Barcelona, Spain), attempting primary closure.

After a healing period of 6 months, a $3 \mathrm{~mm}$ internal, $4 \mathrm{~mm}$ external diameter trephine was used to harvest bone core biopsies from the alveolar crest where implants were prosthetically planned. Implants (Osseospeed ${ }^{\mathrm{TM}}$, Astra Tech, Mölndal, Sweden) were placed in a submerged approach. Dental implants were delivered only if primary stability was attained $132 \mathrm{~N} / \mathrm{cm}^{2}$ of insertion torque). If implant primary stabilization could not be achieved during implant placement, the standard of care was applied: Either placement of a larger (wider, longer, or both) implant in order to achieve stability or abort implant placement at that time, grafting the area (Geistlich Bio-Oss ${ }^{\circledR}$, Geistlich Pharma AG), and allow further healing for an additional period of time (at least 3 months).

\section{Radiographic evaluation}

Standardized digital panoramic X-rays (Kodak ACR-200o, Eastman Kodak Company, Rochester, NY, USA) were obtained at the time of implant placement and 24 months after functional loading in all cases.

A masked examiner (M. P.-M.) measured the distance from the alveolar crest to the most apical part of the graft, using specialized software (DentA-View V I.o, DigiDent, DIT, Nesher, Israel).

\section{Histological and histomorphometrical analyses} Immediately after harvesting, bone core biopsies were fixed in Io\% buffered formalin for $24 \mathrm{~h}$. Then, samples were decalcified (Decalcifier I ${ }^{\mathbb{E}}$, Surgipath Europe Ltd, Peterborough, UK) containing formaldehyde (IO\% w/v), formic acid $(8 \% \mathrm{w})$ $\mathrm{v})$, and methanol ( $\mathrm{I} \% \mathrm{w} / \mathrm{v})$ for $>20$ days, and embedded in paraffin. Bone biopsies were dewaxed, hydrated, and sectioned $(\sim 4 \mu \mathrm{m})$ along the central axis of the core. Sections were processed for hematoxylin-eosin (H-E), teriodic acid Schiff, Masson trichrome, and Goldner trichrome staining. A millimeter scale in the eyepiece of a microscope $\left(\mathrm{BH}_{2}\right.$, Olympus Optical Company Ltd, Tokyo, Japan) with a $\times 40$ objective was used to count osteoblasts, osteoclasts, and osteocytes per $\mathrm{mm}^{2}$. The results were expressed as the mean number of positive cells per $\mathrm{mm}^{2}$. Bone histomorphometric analyses were performed semi-automatically using Masson trichromestained sections. Ten randomized images per sample were captured with a microscope equipped with a $\times$ Io objective and a digital camera (DP7o, Olympus Optical Company Ltd), connected to a computer containing specialized software to perform histomorphometric analysis (Image), NIH, Bethesda, MD, USA, http://rsb.info. nih.gov/ij/). Vital bone, remaining ABB particle, and non-mineralized tissue proportions were quantified separately. The results were expressed as percentages. Bone formation was assessed as a function of the number of osteoid lines in the total core biopsies length.

\section{Immunohistochemical analysis}

Decalcified and paraffin-embedded sections were dewaxed, hydrated, and heat treated in I $\mathrm{mM}$ EDTA buffer for antigenic unmasking in a PT module (Thermo Fisher Scientific, Fremont, CA, USA) at $95^{\circ} \mathrm{C}$ during $20 \mathrm{~min}$. Sections were 
incubated for $60 \mathrm{~min}$ at room temperature with prediluted Osteopontin (OPN), and BMP-4 polyclonal antibodies to identify cellular and interstitial expression, and prediluted monoclonal antibodies $\mathrm{CD}_{5} 6$ [Clone $56 \mathrm{Co}_{4} / \mathrm{I}_{23} \mathrm{~A} 8$ ] to identify osteoblastic cells, tartrate-resistant acid phosphatase (TRAP-I) [Clone 26E5] to identify osteoclast cells and CD68 [Clone KPI] to identify monocytes/macrophages cells, and vimentin [Clone $\mathrm{V}_{9}$ ] to identify mesenchymal cells (positive control). All antibodies were purchased from the same company (Master Diagnóstica, Granada, Spain). Immunohistochemical analysis was performed utilizing an automatic immunostainer (Autostainer 480, Thermo Fisher Scientific) using the polymer-peroxidase-based method, followed by development with diaminobenzidine (Master Diagnóstica). A millimeter scale in the eyepiece of a microscope (BH2, Olympus Optical Company Ltd) with a $\times 40$ objective was used to count positive cells per $\mathrm{mm}^{2}$. Histological, histomorphometrical, and immunohistochemical analyses were conducted by an experienced, masked examiner (F.O.).

\section{Statistical analysis}

Following the descriptive analysis, the $\chi^{2}$ test (for gender, smokers, alcohol consumption, and type of edentulism), and the Mann-Whitney $U$-test (for determining significant differences between treatment groups) were applied; a $P$-value $<0.05$ was considered to be statistically significant. Statistical analyses were performed using statistical analysis software (SPSS-Windows I5.0, SPSS Inc., Chicago, IL, USA).

\section{Results}

\section{Study population}

A total of 28 subjects (I 8 males and io females), with a mean age of $47.3 \pm 9.8$ (ranging from 30 to 72 years), participated in the study. In our series, $28.57 \%$ of the study population was totally edentulous, $71.42 \%$ of the patients were smokers and 7.14\% were alcohol consumers.

Patients were randomly assigned to the two groups ( $n=\mathrm{I} 4$ each), in order to account for these demographical features. Hence, no statistically significant difference among groups existed at baseline, as reflected in Table I. No major complication was recorded in any case. All patients completed the study.

\section{Radiographic findings}

Analysis of the differences between measurements demonstrated statistically significant increased bone resorption in patients from group 2 (0.27 $\pm 0.12 \mathrm{~mm}$ in group I vs. $0.43 \pm 0.7 \mathrm{~mm}$ in group 2; $P=0.033$ Mann-Whitney $U$-test).

Table 1. Study population characteristics

\begin{tabular}{lllll}
\hline Variables & $\begin{array}{l}\text { Group 1 } \\
50 \%[\mathrm{AB}]:\end{array}$ & $\begin{array}{l}\text { Group 2 } \\
20 \%[\mathrm{AB}]:\end{array}$ & $\begin{array}{l}P \text {-values } \chi^{2} \\
\text { Inter-groups }\end{array}$ & $\begin{array}{l}P \text {-values } \chi^{2} \\
\text { intra-groups }\end{array}$ \\
& $50 \%[\mathrm{ABB}]$ & $80 \%[\mathrm{ABB}]$ & & \\
\hline Age & 49.1 & 43.3 & $P=0.155^{*}$ & - \\
Gender (male/female) & $9 / 5$ & $9 / 5$ & 0.769 & 0.144 \\
Smoker (yes/no) & $12 / 2$ & $8 / 6$ & 0.376 & 0.22 \\
Alcohol consumer (yes/no) & $1 / 13$ & $1 / 13$ & 0.671 & 0.001 \\
Totally edentulous (yes/no) & $3 / 11$ & $4 / 10$ & 0.922 & 0.022 \\
\hline
\end{tabular}

${ }^{*}$ Mann-Whitney $U$-test.

$A B$, autologous bone; $A B B$, anorganic bovine bone particles.

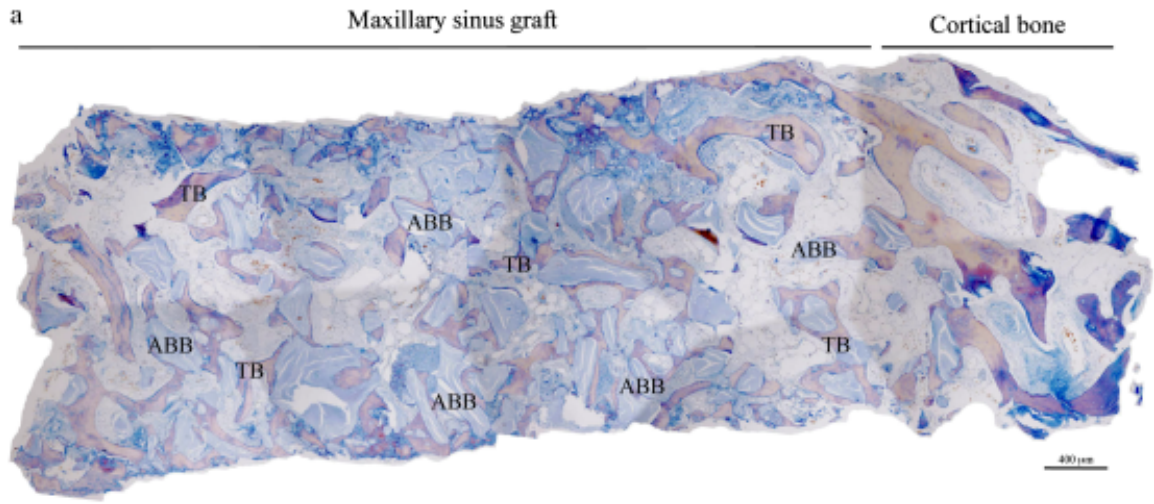

b

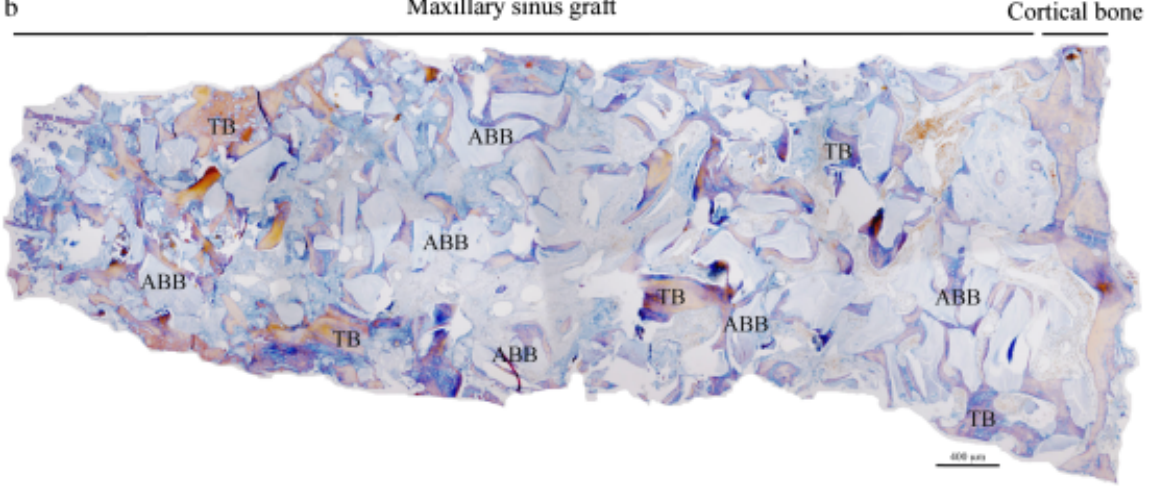

Fig. I. Comparative trephine biopsies from maxillary sinus augmentation of group I (a), and group 2 (b). ABB, anorganic bovine bone particles; TB, trabecular bone. Scale bar $400 \mu \mathrm{m}$ (Masson trichrome).

Histological and histomorphometrical analyses

All biopsy samples presented similar dimensions, ranging from $\mathrm{I} 3$ to $\mathrm{I} 5 \mathrm{~mm}$ of length (Fig. I). Histomorphometric analysis of group I samples revealed that the mean proportion of vital bone was $36 \pm 9.44 \%$, average proportion of nonmineralized tissue was $44.8 \pm \mathrm{I} 3.5 \mathrm{I} \%$, and $19.36 \pm \mathrm{I} 4.58 \%$ was the mean value for remaining $\mathrm{ABB}$ particles. Mean numbers of osteoblasts and osteoclasts found per $\mathrm{mm}^{2}$ were I60.I I \pm 220.89 and I06.38 \pm I73.I I, respectively. Interestingly, mean osteocyte count per $\mathrm{mm}^{2}$ was $631.85 \pm 607.98$. On the other hand, analysis of samples obtained from group 2 revealed that the mean proportion of vital bone was $37.38 \pm$ $17.46 \%$, the mean percentage of non-mineralized tissue content was $31.92 \pm 16.05 \%$, and aver- age proportion of remaining $\mathrm{ABB}$ particles was $30.75 \pm \mathrm{I} 8.5 \mathrm{I} \%$. Mean numbers of osteoblasts and osteoclasts found per $\mathrm{mm}^{2}$ were $75.27 \pm$ 58.89 and 50.4I \pm 33.87, respectively. Mean value after osteocyte count was 2 I9.08 \pm I03.26. No significant differences between groups were observed in relation to vital bone, and non-mineralized tissue (Table 2). While tissue compartments values did not show statistically significant differences between both graft mixtures, osteoid lines were significantly more abundant in the composite with higher quantity of vital bone (I8.05 \pm I0.06 in group $\mathrm{I}$ vs. $9.01 \pm 7.53$ in group 2; $P=0.023$, Mann-Whitney $U$-test) (Fig. 2). Similarly, group I samples exhibited more cellular presence in all analyzed parameters as compared with group 2 specimens 
(Table 2). Nonetheless differences were statistically significant only regarding the number of osteocytes per $\mathrm{mm}^{2}(P=0.002$, Mann-Whitney $U$-test).

\section{Immunohistochemical analysis}

Interestingly, no statistically significant difference between groups with regard to the expression of any of the immunohistochemical markers tested in this study (CD56, TRAP-I, CD68, and BMP-4) was observed. Regarding TRAP-I expression, we found the presence of a higher number of osteoclasts per $\mathrm{mm}^{2}$ (TRAP-I positive) in group 2 samples $(86.58 \pm 6$ I.8I vs. $109.96 \pm 62.38, \quad P=0.25)$. Furthermore, a higher number of osteoclasts per ABB particles as identified in samples from group 2 (I.52 \pm I.5 vs. $2.59 \pm$ I.5, $P=0.06)$ predominantly surrounding $\mathrm{ABB}$ particles (Fig. 3). CD68 expression in osteoclasts cells was similar in both groups (Fig. 4). BMP-4 was expressed in some osteocytes of vital bone (cortical and trabecular), osteoclasts, and osteoblasts for both groups, but not in all cases (Fig. 5). OPN was expressed in vital bone (cortical and trabecular) and in the cement lines between remaining $\mathrm{ABB}$ particles and vital bone, particularly in samples from group I, and significant differences were observed among groups ( $0.68 \pm 0.25$ in group I vs. O. I $\pm 0.3 \mathrm{I}$, in group 2; $P=$ o.or3, Mann-Whitney $U$-test). A clear OPN expression was observed in osteocytes present in vital bone in group I specimens (Fig. 6). On the other hand, a robust expression of OPN- and TRAP-I-positive cells was observed in the surface of $\mathrm{ABB}$ particles in specimens from group 2 (Figs 3 and 6).

\section{Discussion}

One of the critical aspects of any bone grafting procedure is the selection of the biomaterial, considering the goal of the intervention, individual patient features, anatomic location, defect morphology, and the properties of the material itself. $\mathrm{ABB}$ has been regarded as an excellent biomaterial for sinus augmentation given its osteoconductive properties (Hallman et al. 2002a), structural stability (Schlegel et al. 2003), and long-term positive clinical response (Mayfield et al. 200I). However, this biomaterial does not have the capacity to interact with titanium to promote osseointegration (Valentini et al. I998; Rosenlicht \& Tarnow I999). Theoretically, this could imply that grafts containing elevated proportions of $\mathrm{ABB}$ may not be adequate to achieve an optimal bone-to-implant contact (Haas et al. I998). Smiler et al. (1992) reported that bone formation was faster using a composite graft of $\mathrm{ABB}$ granules and $\mathrm{AB}$ than with the application of $\mathrm{ABB}$ as a sole grafting material. In a different study,
Table 2. Comparison of morphometrical variables between groups

\begin{tabular}{lccc} 
Morphometric variables & Group 1 & Group 2 & P-values* \\
& $50 \%[\mathrm{AB}]:$ & $20 \%[\mathrm{AB}]:$ & \\
& $50 \%[\mathrm{ABB}]$ & $80 \%[\mathrm{ABB}]$ & \\
\hline Vital bone (\%) & $36 \pm 9.44$ & $37.38 \pm 17.46$ & 0.114 \\
ABB particles $(\%)$ & $19.36 \pm 14.58$ & $30.75 \pm 18.51$ & 0.013 \\
Non-mineralized tissue (\%) & $44.8 \pm 13.51$ & $31.92 \pm 16.05$ & 0.324 \\
Osteoblast cells $\left(\mathrm{mm}^{2}\right)$ & $160.11 \pm 220.89$ & $75.27 \pm 58.89$ & 0.531 \\
Osteoclast cells $\left(\mathrm{mm}^{2}\right)$ & $106.38 \pm 173.11$ & $50.41 \pm 33.87$ & 0.327 \\
Osteocytes $\left(\mathrm{mm}^{2}\right)$ & $631.85 \pm 607.98$ & $219.08 \pm 103.26$ & 0.002 \\
Osteoid lines & $18.05 \pm 10.06$ & $9.01 \pm 7.53$ & 0.023
\end{tabular}

Values are expressed as mean \pm standard deviation.

*Mann-Whitney U-test.

$A B$, autologous bone; $A B B$, anorganic bovine bone particles.

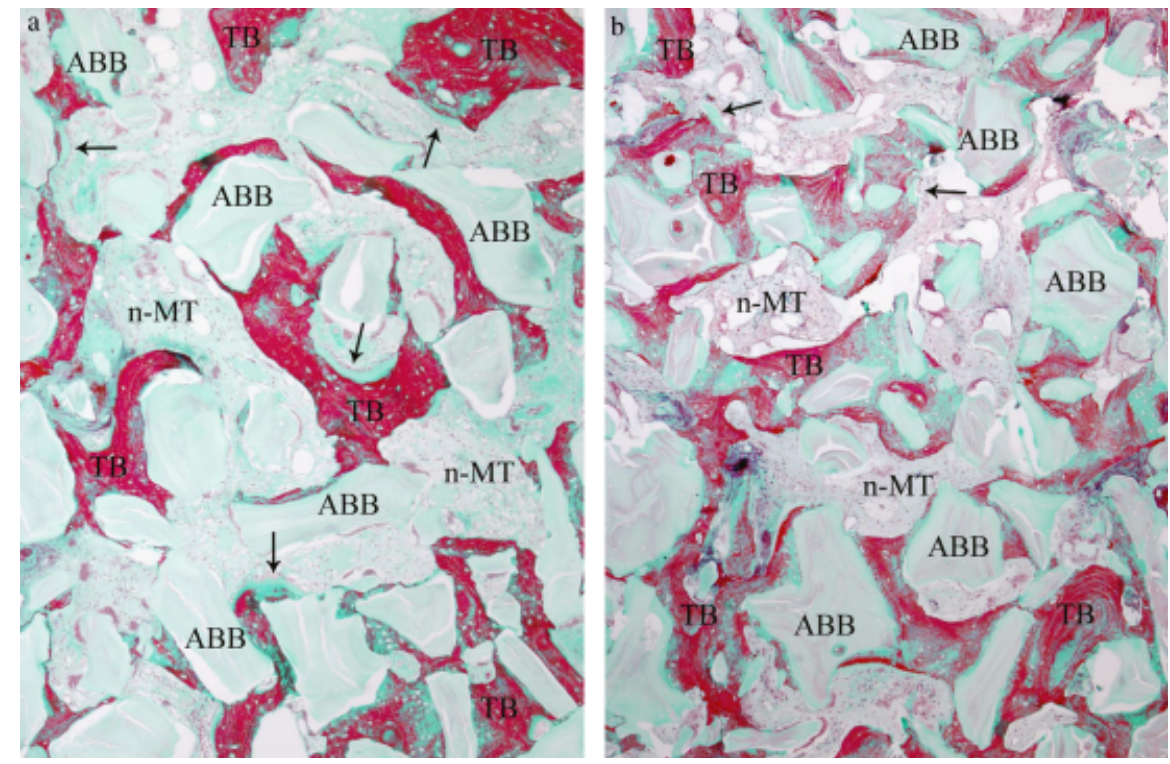

Fig. 2. Morphological features of composite maxillary sinus graft after 6 months. Note the numerous osteoid lines (arrows) in group I $(50 \%[\mathrm{AB}]: 50 \%[\mathrm{ABB}]$ ratio) (a) in comparison with group $2(20 \%[\mathrm{AB}]: 80 \%[\mathrm{ABB}]$ ratio) $(\mathrm{b})$. ABB, anorganic bovine bone particles; TB, trabecular bone; $\mathrm{n}-\mathrm{MT}$, non-mineralized tissue (Masson trichrome $\times 40$ ).
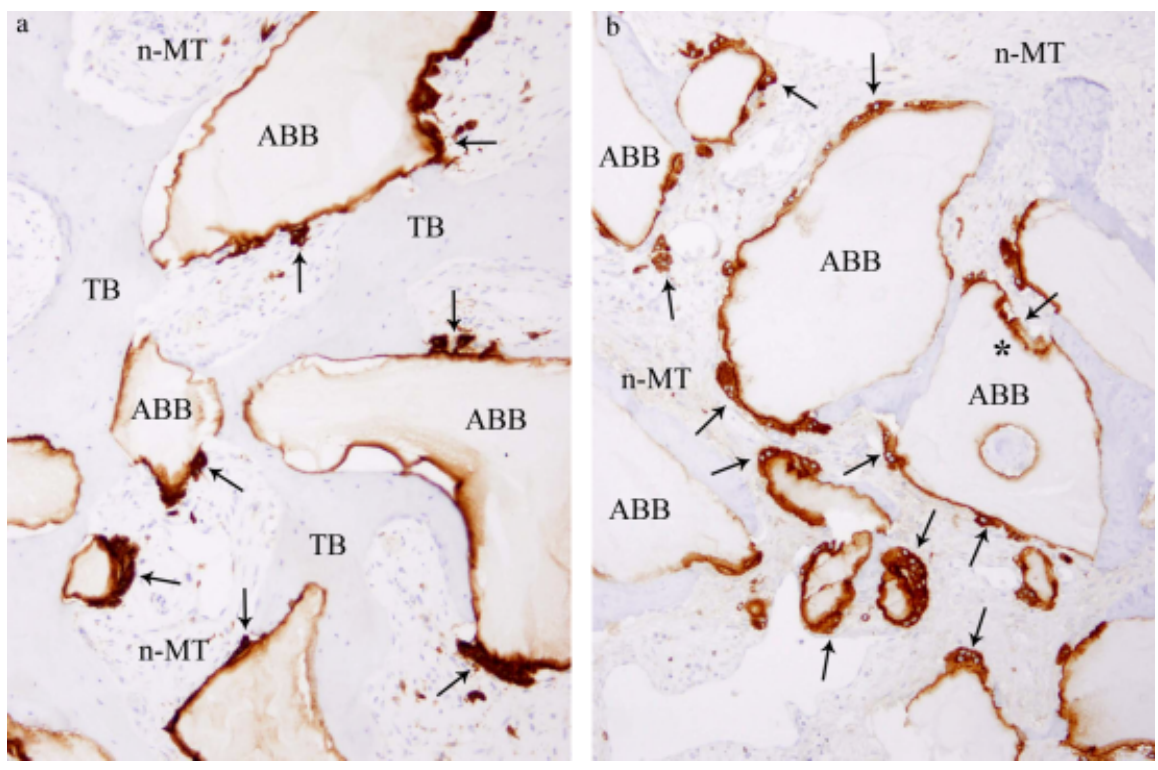

Fig. 3. Identification of osteoclasts cells (arrows) locates principally around ABB particles by means of immunohistochemical tartrate-resistant acid phosphatase (TRAP-I) expression. In group I (a), there are less than group 2 (b) osteoclasts cells per ABB particle and per millimeter square. Note TRAP-I deposit in resorption edge of ABB particles(asterisk). ABB, anorganic bovine bone particles; TB, trabecular bone; n-MT, non-mineralized tissue (polymer-peroxidase-based method $\times$ IOo). 

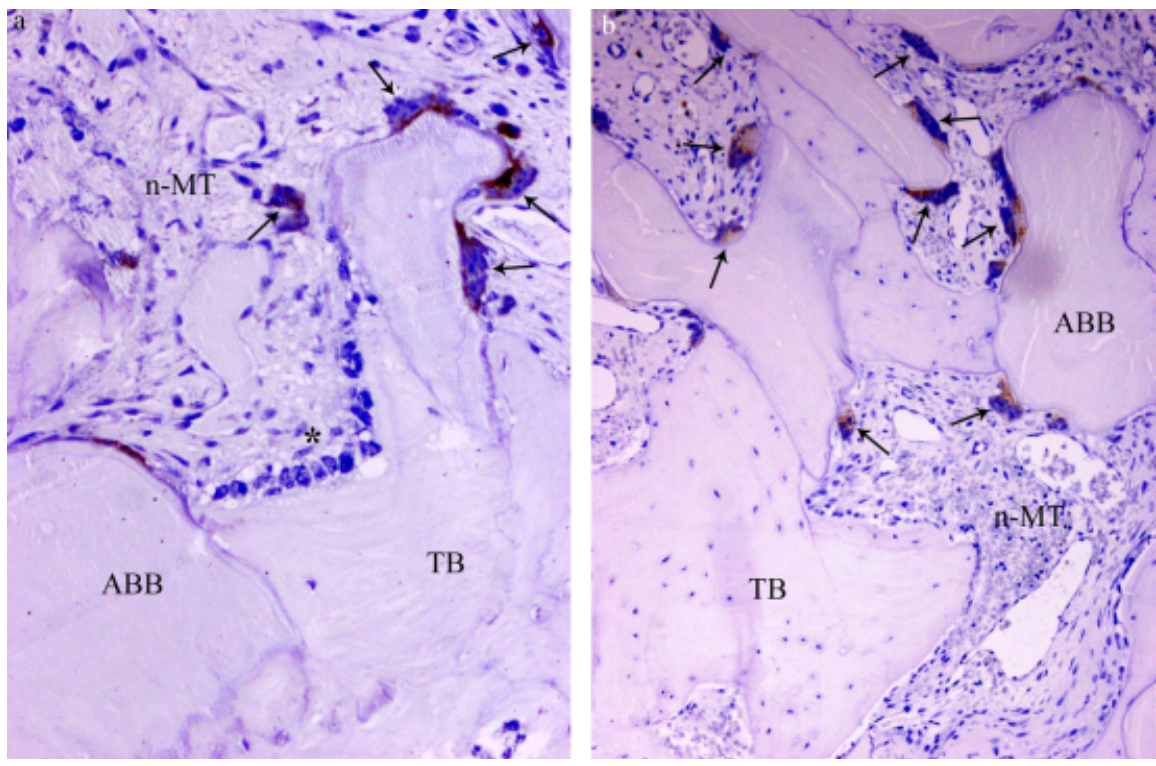

Fig. 4. CD68 expression in osteoclasts cells (arrows). (a) Group I [50 : $50 \mathrm{AB}$ to ABB ratio] (*osteoblast cells) (polymerperoxidase-based method $\times 200$ ). (b) Group 2 [20:80 AB to ABB ratio] (polymer-peroxidase-based method $\times$ IOO). ABB, anorganic bovine bone particles; $\mathrm{TB}$, trabecular bone; $\mathrm{n}-\mathrm{MT}$, non-mineralized tissue.
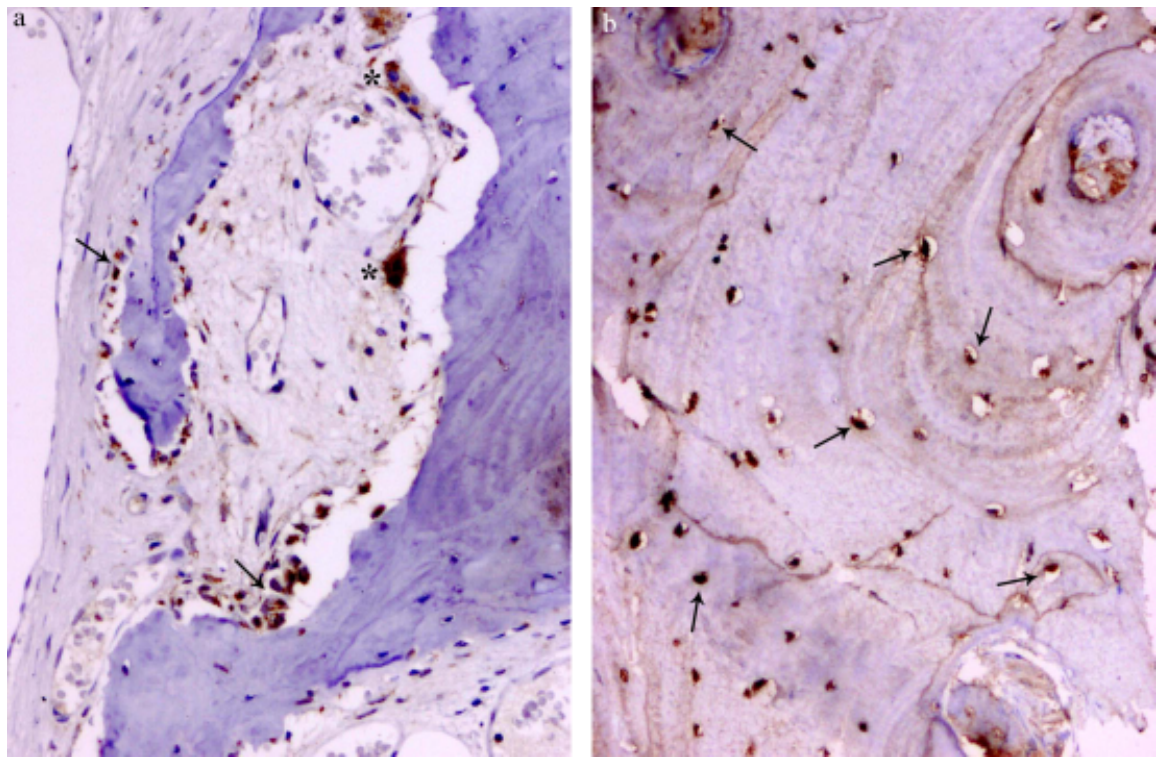

Fig. 5. BMP-4 expression. (a) Positives osteoblasts (arrows), and osteoclasts (asterisk). (b) Positives osteocytes (arrows) in cortical bone (polymer-peroxidase-based method $\times 200)$.

Tadjoedin et al. (2003) compared different $A B$ to $\mathrm{ABB}$ ratios in a human model and indicated that the final amount of vital bone formed during the healing period correlated inversely with the proportion of $\mathrm{ABB}$ particles present in the graft. However, a limitation of these studies was the low number of patients included. Thorwarth and colleagues evaluated graft maturation using either $\mathrm{ABB}$ alone or a composite of $\mathrm{ABB}$ and $\mathrm{AB}(75 \%$ to $25 \%$, respectively) in an animal model. The addition of autogenous bone to $\mathrm{ABB}$ resulted in higher initial proportion of vital bone. It was concluded that $25 \% \mathrm{AB}$ was an adequate proportion to induce increased bone formation(Thorwarth et al. 2006). Interestingly, Hallman et al. (2002 b) showed in a human study that among using $\mathrm{AB}, \mathrm{ABB}$, and a combination of them, the best results in terms of bone-to-implant contact and vital bone area were achieved when both biomaterials were combined in a $20 \%[\mathrm{AB}]: 80 \%[\mathrm{ABB}]$ ratio.

The present study was conducted to determine if the use of two different $\mathrm{AB}$ to $\mathrm{ABB}$ ratios (50:50 or 20:80) may affect graft consolidation and bone remodeling after sinus augmentation. Bone core biopsies were harvested after a healing period of 6 months, at the time of implant placement, in order to investigate the characteristics of these tissues. Analysis of the proportion of newly formed vital bone in human histological samples has been traditionally accepted as a valid method to evaluate sinus augmentation outcomes (Wallace et al. I996). Other morphometrical and immunohistochemical parameters (i.e. osseous cells count, OPN and TRAP-I expression) have also proven to be useful in assessing the bone remodeling response after the process of graft maturation (Galindo-Moreno et al. 20IOa). Hence, vital bone, non-mineralized tissue, and remaining $\mathrm{ABB}$ particles proportion, as well as the number of osteoblasts, osteoclasts, osteocytes, osteoid lines, and the expression of several molecular markers were determined in our samples.

After histomorphometric analysis, similar mean vital bone proportion was observed for both groups. However, vital bone percentage was very slightly higher in samples containing a higher ABB proportion $(36 \pm 9.44 \%$ vs. $37.38 \pm \mathrm{I} 7.46 \%)$. Our findings are in accordance with the data reported by Hallman et al. (2002b) $(37.7 \pm 31.3 \%$ [100\% $\mathrm{AB}] ; 39.9 \pm 8 \%[20 \% \mathrm{AB}: 80 \% \mathrm{ABB}] ; 4 \mathrm{I} .7 \pm$ $26.6 \%$ [100\% ABB]). This finding may be explained because $\mathrm{ABB}$ appear to act as a guidance to osteogenic cells from pre-existing bone surfaces of the sinus floor along the surface of the grafted ABB particles (Tadjoedin et al. 2003). Nevertheless, cell populations were found to be quite different in both graft mixtures. Osteoid lines were more abundant in the composite graft with higher quantity of $\mathrm{AB}$. Likewise, more cellularity was observed in samples obtained from group I in comparison with specimens from group 2. This included all the cellular components analyzed (osteoblasts, osteoclasts, and osteocytes), although the difference was statistically significant only for the number of osteocytes. Our results suggest that bone metabolism may be more intense in grafts containing higher baseline vital bone proportions, as indicated by Smiler et al. (I992). This tissue response can be attributed to the presence of $A B$, which may act as a local source of cells and bone matrix proteins with osteoinductive properties (Thorwarth et al. 2006).

A remarkable finding in our study was the distribution of OPN. OPN is involved in a variety of biologic events, including cell-binding activity (Milam et al. I99I) and bone angiogenesis (Matusan-Ilijas et al. 2008). OPN is secreted not only by cells of the osteoblastic lineage (Zohar et al. I997) but also by osteocytes (McKee \& Nanci I995; Sodek et al. I995). In our samples, OPN was expressed markedly in osteocytes present in vital bone in specimens containing more $A B$ (group I). It is important to remember that a statistically significant difference in the number of osteocytes was observed between 

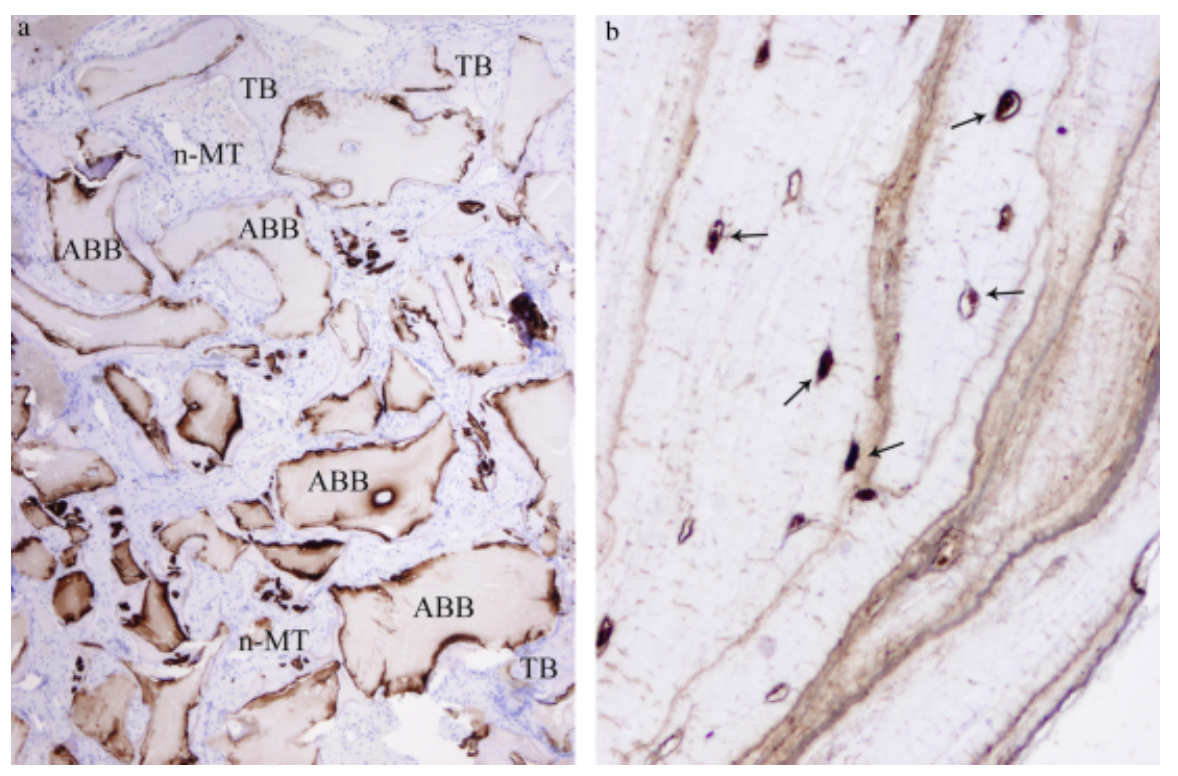

Fig. 6. Osteopontin (OPN) expression. (a) OPN deposits surrounding ABB particles in group I (dark lines) (polymerperoxidase-based method $\times 40$ ). (b) OPN expression in osteocytes of trabecular bone (arrows) principally in group I (polymerperoxidase-based method $\times 400)$. ABB, anorganic bovine bone particles; TB, trabecular bone; n-MT, non-mineralized tissue.

Similar patterns of OPN and TRAP-I expression intra-groups but different patterns intergroups, may indicate that the proportion of $\mathrm{ABB}$ directly influences the net resorption of this xenogenic material. Owing to its scaffolding properties and its low resorption index, $\mathrm{ABB}$ may contribute significantly to prevent volume loss in grafted areas. While some authors have indicated that $\mathrm{ABB}$ particles barely undergo resorption (Mordenfeld et al. 20Io), our results from this and previous studies, as well as others reported by authors (Perrotti et al. 2009), contradict this concept. Results presented in this study show that the higher initial quantity of $\mathrm{ABB}$ particles, the more the OPN and TRAP-I expression found in the remaining particles. However, in spite of comprising less cellularity, a greater number of osteoclasts expressing TRAP-I over these particles (I.52 \pm I.5 vs. $2.59 \pm$ I.5, $P=0.06$ ) were observed in samples from group 2. Radiographic findings support this concept, given the increased average resorption observed in group 2 .

\section{Conclusions}

groups in favor of group I $(P=0.002$, MannWhitney $U$-test). Likewise, the mean number of osteoid lines was twice as much in the group with higher quantity of vital bone. Taking in consideration this information and the critical role that osteocytes play in orchestrating bone metabolism (Bonewald 2006), this distinctive pattern of OPN expression may indicate that osteocyte-derived OPN may be utilized in the cement line for osteoblast adhesion or to guide early calcification events at this junction (Ganss et al. I999).

Interestingly, a marked expression of OPN on ABB particles was observed in samples from group 2. This distribution of OPN throughout the anorganic bone matrix may influence osteoclast activity during resorption and maturation of woven bone (Sodek et al. 2000). There is strong evidence supporting the role of OPN in the formation (Yamate et al. I997), migration (Noda et al. I998), attachment (Katayama et al. I998), and regulation of the resorptive activity of osteoclasts (Duong \& Rodan I 999). Understanding of the role of OPN as a regulator of bone remodeling is a very interesting topic because the mechanisms that govern the dual behavior of
OPN remain unclear, as this protein can regulate bone resorptive or osteogenic processes.

TRAP-I protein is a specific marker for osteoclastic cells activity. The presence of a higher number of osteoclasts TRAP-I positive per $\mathrm{mm}^{2}$ was observed in group 2 samples. Furthermore, more osteoclasts per ABB particles were identified in samples from group 2 and predominantly surrounding $\mathrm{ABB}$ particles (Fig. 3); however, these differences were not statistically significant. Regarding these findings, Tadjoedin et al. (2003) related the presence of many TRAP-positive multinucleated cells against the ABB granules, which may suggest that $\mathrm{ABB}$ granules were gradually degraded and resorbed by the activity of osteoclasts. Interestingly, in our study, TRAP-Ipositive cell distribution showed a similar pattern to OPN expression. Osteoclast migration and attachment is determined by phosphorylated OPN, and this biological event is regulated by the endogenous TRAP-I (Ek-Rylander \& Andersson 2009). This finding confirms that OPN not only plays a major role in osteoclast activation but also facilitates osteoclast migration as suggested previously (Razzouk et al. 2002).
$A B$ to $A B B$ ratio was found to influence bone remodeling patterns and cell content following sinus augmentation procedures. A similar proportion of vital bone was found in specimens obtained from both groups. However, more cellular activity was observed in samples containing more $\mathrm{AB}$.

Acknowledgements: We would like to acknowledge Prof. Catena (School of Psychology, University of Granada), Prof. Francisco Mesa (School of Dentistry, University of Granada), Prof. Mercedes Gallas (School of Dentistry, University of Santiago de Compostela), María Dolores Rodríguez, and Mohamed Tassi, laboratory technicians at the Department of Pathology of the University of Granada and Institute of Biopathology and Regenerative Medicine (IBIMER), for their valuable contribution to this study.

Disclaimer: Authors declare having no conflict of interest, either directly or indirectly in any of the companies or products listed in the study. This investigation was partially supported in part by Research Group \#CTS-I 38 and \#CTS 583 (Junta de Andalucia, Spain).

\section{References}

Bonewald, L. (2006) Osteocytes as multifunctional cells. Journal of Musculoskeletal and Neuronal Interactions 6: 33 I-333

Boyne, P.J. \& James, R.A. (I980) Grafting of the maxillary sinus floor with autogenous marrow and bone. Journal of Oral Surgery 38: 6I 3-6I 6.
Browaeys, H., Bouvry, P. \& De Bruyn, H. (2007) A literature review on biomaterials in sinus augmentation procedures. Clinical Implant Dentistry ef Related Research 9: I66-I77.

Del Fabbro, M., Testori, T., Francetti, L. \& Weinstein, R. (2004) Systematic review of survival rates for implants placed in the grafted maxillary sinus. The International Journal of Periodontics et Restorative Dentistry 24: 565-577.

Duong, L.T. \& Rodan, G.A. (I999) The role of integrins in osteoclast function. Journal of Bone and Mineral Metabolism I7: I-6. 
Ek-Rylander, B. \& Andersson, G. (2009) Osteoclast migration on phosphorylated osteopontin is regulated by endogenous tartrate-resistant acid phosphatase. Experimental Cell Research 316: 443-465.

Ferreira, C.E., Novaes, A.B., Haraszthy, V.I., Bittencourt, M., Martinelli, C.B. \& Luczyszyn, S.M. (2009) A clinical study of 406 sinus augmentations with IOO\% anorganic bovine bone. Journal of Periodontology 80: 1920-1927.

Galindo-Moreno, P., Avila, G., Fernandez-Barbero, J.E., Aguilar, M., Sanchez-Fernandez, E., Cutando, A. \& Wang, H.L. (2007) Evaluation of sinus floor elevation using a composite bone graft mixture. Clinical Oral Implants Research I8: 376-382.

Galindo-Moreno, P., Avila, G., Fernandez-Barbero, J.E., Mesa, F., O'Valle-Ravassa, F. \& Wang, H.L. (2008) Clinical and histologic comparison of two different composite grafts for sinus augmentation: a pilot clinical trial. Clinical Oral Implants Research I9: 755-759.

Galindo-Moreno, P., Fauri, M., Avila-Ortiz, G., Fernandez-Barbero, J.E., Cabrera-Leon, A. \& Sanchez-Fernandez, E. (2005) Influence of alcohol and tobacco habits on peri-implant marginal bone loss: a prospective study. Clinical Oral Implants Research I6: 579-586.

Galindo-Moreno, P., Moreno-Riestra, I., Avila, G., Fernandez-Barbero, J.E., Mesa, F., Aguilar, M., Wang, H.L. \& O'Valle, F. (20IOa) Histomorphometric comparison of maxillary pristine bone and composite bone graft biopsies obtained after sinus augmentation. Clinical Oral Implants Research 2 I: I22-I 28.

Galindo-Moreno, P., Padial-Molina, M., Fernandez-Barbero, J.E., Mesa, F., Rodríguez-Martínez, D. \& $\mathrm{O}^{\prime}$ Valle, F. (20IOb) Optimal microvessel density from composite graft of autogenous maxillary cortical bone and anorganic bovine bone in sinus augmentation: influence of clinical variables. Clinical Oral Implants Research 21: 22 I-227.

Ganss, B., Kim, R.H. \& Sodek, J. (1999) Bone sialoprotein. Critical Reviews in Oral Biology and Medicine Io: 79-98.

Haas, R., Donath, K., Fodinger, M. \& Watzek, G. (I998) Bovine hydroxyapatite for maxillary sinus grafting: comparative histomorphometric findings in sheep. Clinical Oral Implants Research 9: 107-I I6.

Hallman, M., Hedin, M., Sennerby, L. \& Lundgren, S. (2002a) A prospective I-year clinical and radiographic study of implants placed after maxillary sinus floor augmentation with bovine hydroxyapatite and autogenous bone. The International Journal of Oral and Maxillofacial Surgery 6o: 277-284.

Hallman, M., Sennerby, L. \& Lundgren, S. (2002b) A clinical and histologic evaluation of implant integration in the posterior maxilla after sinus floor augmentation with autogenous bone, bovine hydroxyapatite, or a 20:80 mixture. The International Journal of Oral 4) Maxillofacial Implants 17: 635-643.

Katayama, Y., House, C.M., Udagawa, N., Kazama, J.J., McFarland, R.J., Martin, T.J. \& Findlay, D.M. (I998) Casein kinase 2 phosphorylation of recombinant rat osteopontin enhances adhesion of osteoclasts but not osteoblasts. Journal of Cellular Physiology $\mathbf{1 7 6}$ : I79-I 87

Levin, L., Herzberg, R., Dolev, E. \& Schwartz-Arad, D. (2004) Smoking and complications of onlay bone grafts and sinus lift operations. The International Journal of Oral et) Maxillofacial Implants I9: 369-373.

Lundgren, S., Andersson, S., Gualini, F. \& Sennerby, L. (2004) Bone reformation with sinus membrane elevation: a new surgical technique for maxillary sinus floor augmentation. Clinical Implant Dentistry ↔ Related Research 6: 165-173.

Martos Diaz, P., Naval Gias, L., Sastre Perez, J., Gonzalez Garcia, R., Bances del Castillo, F., Mancha de la Plata, M., Galindo Moreno, P. \& Munoz Guerra, M. (2007) Sinus elevation by in situ utilization of bone scrapers: technique and results. Medicina Oral, Patología Oral y Cirugía Bucal I2: E537-E54I. Matusan-Ilijas, K., Behrem, S., Jonjic, N., Zarkovic, K. \& Lucin, K. (2008) Osteopontin expression correlates with angiogenesis and survival in malignant astrocytoma. Pathology Oncology Research I4: 293-298.

Mayfield, L.J., Skoglund, A., Hising, P., Lang, N.P. \& Attstrom, R. (200I) Evaluation following functional loading of titanium fixtures placed in ridges augmented by deproteinized bone mineral. A human case study. Clinical Oral Implants Research I2: 508-5 I4.

McKee, M.D. \& Nanci, A. (I995) Osteopontin and the bone remodeling sequence. Colloidal-gold immunocytochemistry of an interfacial extracellular matrix protein. Annals of the New York Academy of Sciences 760: 177-I89.

Milam, S.B., Haskin, C., Zardeneta, G., Chen, D., Magnuson, V.L., Klebe, R.J. \& Steffenson, B. (I99I) Cell adhesion proteins in oral biology. Critical Reviews in Oral Biology and Medicine 2: 45 I-49I.

Mordenfeld, A., Hallman, M., Johansson, C.B. \& Albrektsson, T. (2010) Histological and histomorphometrical analyses of biopsies harvested I I years after maxillary sinus floor augmentation with deproteinized bovine and autogenous bone. Clinical Oral Implants Research 21: 96I-970.

Nkenke, E. \& Stelzle, F. (2009) Clinical outcomes of sinus floor augmentation for implant placement using autogenous bone or bone substitutes: a systematic review. Clinical Oral Implants Research 20 (Suppl. 4): I24-I33. Noda, M., Rittling, S.R., Muguruma, Y., Asou, Y., Yoshitake, H. \& Tsuji, K. (I998) Osteopontin-deficient mice (OD-) cells exhibit enhanced actin fiber formation and spreading while OD-osteoclasts are less efficient in removing hydroxyapatite coated on glass and in recruitment to ectopically implanted bone matrix (abstract). Journal of Biomedical Materials Research 23: S220.

O'Leary, T.J., Drake, R.B. \& Naylor, J.E. (I972) The plaque control record. Journal of Periodontology 43: 38. Peleg, M., Garg, A.K., Misch, C.M. \& Mazor, Z. (2004) Maxillary sinus and ridge augmentations using a surfacederived autogenous bone graft. The International Journal of Oral and Maxillofacial Surgery 62: I 535-I 544.

Perrotti, V., Nicholls, B.M., Horton, M.A. \& Piattelli, A. (2009) Human osteoclast formation and activity on a xenogenous bone mineral. Journal of Biomedical Materials Research. Part A 90: 238-246.

Razzouk, S., Brunn, J.C., Qin, C., Tye, C.E., Goldberg, H.A. \& Butler, W.T. (2002) Osteopontin posttranslational modifications, possibly phosphorylation, are required for in vitro bone resorption but not osteoclast adhesion. Bone 30: 40-47.

Rios, H.F., Avila, G., Galindo, P., Bratu, E. \& Wang, H.L. (2009) The influence of remaining alveolar bone upon lateral window sinus augmentation implant survival. Implant Dentistry I8: 402-4I 2.

Rosenlicht, J.L. \& Tarnow, D.P. (I999) Human histologic evidence of integration of functionally loaded hydroxyapatite-coated implants placed simultaneously with sinus augmentation: a case report 2 I/ 2 years postplacement. The Journal of Oral Implantology 25: 7-IO.
Sartori, S., Silvestri, M., Forni, F., Cornaglia, A.I., Tesei, P. \& Cattaneo, V. (2003) Ten-year follow-up in a maxillary sinus augmentation using anorganic bovine bone (Bio-Oss). A case report with histomorphometric evaluation. Clinical Oral Implants Research I4: 369-372.

Schlegel, K.A., Fichtner, G., Schultze-Mosgau, S. \& Wiltfang, J. (2003) Histologic findings in sinus augmentation with autogenous bone chips versus a bovine bone substitute. The International Journal of Oral e) Maxillofacial Implants I8: 53-58.

Schuklenk, U. \& Ashcroft, R. (2000) International research ethics. Bioethics I4: I 58-172.

Smiler, D.G., Johnson, P.W., Lozada, J.L., Misch, C., Rosenlicht, J.L., Tatum, O.H. Jr \& Wagner, J.R. (1992) Sinus lift grafts and endosseous implants. Treatment of the atrophic posterior maxilla. Dental Clinics of North America 36: I5 I-I86; discussion I 87-I 58 .

Sodek, J., Chen, J., Nagata, T., Kasugai, S., Todescan, R. Jr, Li, I.W. \& Kim, R.H. (I995) Regulation of osteopontin expression in osteoblasts. Annals of the New York Academy of Sciences 760: 223-24I.

Sodek, J., Ganss, B. \& McKee, M.D. (2000) Osteopontin. Critical Reviews in Oral Biology and Medicine II: 279-303.

Soltan, M. \& Smiler, D.G. (2005) Antral membrane balloon elevation. The Journal of Oral Implantology 3I: 85-90.

Tadjoedin, E.S., de Lange, G.L., Bronckers, A.L., Lyaruu, D.M. \& Burger, E.H. (2003) Deproteinized cancellous bovine bone (Bio-Oss) as bone substitute for sinus floor elevation. A retrospective, histomorphometrical study of five cases. Journal of Clinical Periodontology 30: 26I-270.

Thorwarth, M., Schlegel, K.A., Wehrhan, F., Srour, S. \& Schultze-Mosgau, S. (2006) Acceleration of de novo bone formation following application of autogenous bone to particulated anorganic bovine material in vivo. Oral Surgery, Oral Medicine, Oral Pathology, Oral Radiology and Endodontics Ior: 309-316.

Traini, T., Valentini, P., Iezzi, G. \& Piattelli, A. (2007) A histologic and histomorphometric evaluation of anorganic bovine bone retrieved 9 years after a sinus augmentation procedure. Journal of Periodontology 78: $955-96 \mathrm{I}$.

Valentini, P., Abensur, D., Densari, D., Graziani, J.N. \& Hammerle, C. (I998) Histological evaluation of Bio-Oss in a 2-stage sinus floor elevation and implantation procedure. A human case report. Clinical Oral Implants Research 9: 59-64.

Vercellotti, T., De Paoli, S. \& Nevins, M. (200I) The piezoelectric bony window osteotomy and sinus membrane elevation: introduction of a new technique for simplification of the sinus augmentation procedure. The International Journal of Periodontics $\leftrightarrow$ Restorative Dentistry 2I: 56I-567.

Wallace, S.S. \& Froum, S.J. (2003) Effect of maxillary sinus augmentation on the survival of endosseous dental implants. A systematic review. Annals of Periodontology 8: 328-343.

Wallace, S.S., Froum, S.J., Cho, S.C., Elian, N., Monteiro, D., Kim, B.S. \& Tarnow, D.P. (2005) Sinus augmentation utilizing anorganic bovine bone (Bio-Oss) with absorbable and nonabsorbable membranes placed over the lateral window: histomorphometric and clinical analyses. The International Journal of Periodontics \& Restorative Dentistry 25: 55I-559. 
Wallace, S.S., Froum, S.J. \& Tarnow, D.P. (I996) Histologic evaluation of a sinus elevation procedure: a clinical report. The International Journal of Periodontics et) Restorative Dentistry I6: 46-5 I.

Wang, H.L. \& Katranji, A. (2008) ABC sinus augmentation classification. The International Journal of Periodontics e) Restorative Dentistry 28: 383-389.

Watzek, G., Fürst, G. \& Gruber, R. (2006) Biologic basis of sinus grafting. In: Jensen, O.T., ed. The Sinus Bone Graft. Ist edition, I3-26. Hanover Park, IL: Quintessence Books.
Wheeler, S.L. (I997) Sinus augmentation for dental implants: the use of alloplastic materials. The International Journal of Oral and Maxillofacial Surgery 55: I287-I293.

Yamate, T., Mocharla, H., Taguchi, Y., Igietseme, J.U., Manolagas, S.C. \& Abe, E. (I997) Osteopontin expression by osteoclast and osteoblast progenitors in the murine bone marrow: demonstration of its requirement for osteoclastogenesis and its increase after ovariectomy. Endocrinology $\mathbf{1 3 8}$ : 3047-3055.
Yildirim, M., Spiekermann, H., Handt, S. \& Edelhoff, D. (200I) Maxillary sinus augmentation with the xenograft Bio-Oss and autogenous intraoral bone for qualitative improvement of the implant site: a histologic and histomorphometric clinical study in humans. The International Journal of Oral \&) Maxillofacial Implants I6: 23-33.

Zohar, R., Lee, W., Arora, P., Cheifetz, S., McCulloch, C. \& Sodek, J. (I997) Single cell analysis of intracellular osteopontin in osteogenic cultures of fetal rat calvarial cells. Journal of Cellular Physiology 170: 88-ıoo. 